\title{
VERONESE, Marilia Verissimo; GUARESCHI, Pedrinho A. (Orgs.). Psicologia do cotidiano: representações sociais em ação. Petrópolis, RJ: Vozes, 2007. 312 p.
}

\author{
Patricia Caldeira Tolentino*
}

\begin{abstract}
Psicologia do cotidiano: representações sociais em ação é uma publicação organizada por Marília Veríssimo Veronese e Pedrinho A. Guareschi e compõe a Coleção Psicologia Social, da Editora Vozes. A obra é constituída de 11 artigos de pesquisadores brasileiros que trazem contribuições para a conexão da Psicologia Social e da teoria das Representações Sociais com o movimento da vida cotidiana. Apresenta-se como um importante subsídio para as pesquisas em representações sociais, pela investida de estabelecer um elo entre a subjetividade e a objetividade dos campos históricos e sociais, em uma tentativa de articular as categorias representações sociais e o cotidiano.
\end{abstract}

$\mathrm{O}$ artigo de Pedrinho A. Guareschi abre a publicação trazendo o germe da Psicologia Social, por meio das teorias que surgiram em torno do seu desenvolvimento, e refletindo sobre como essas teorias tentaram abarcar o psicossocial. Primeiramente traz o movimento histórico da Psicologia, a partir do século XIX, marcado pelo seu surgimento com Wundt, e depois a caracterização da Psicologia Social como alongamento dessa psicologia. O autor enfoca as influências do materialismo cientificista e do individualismo cartesiano, que trouxeram uma concepção da Psicologia como ciência experimental, apresentando uma análise do indivíduo separada de seus contextos sociais. Nessa época, mesmo com as tentativas de trazer à Psicologia Social o imaterial, o psíquico, o simbólico e o representacional, os estudiosos americanos a descaracterizaram a partir do modelo individualista, em um predomínio que durou até a década de 1950 . Na sequência, a estruturação da Psicologia Social é realizada a partir de 1950, principalmente em torno de Serge Moscovici, que começa a questionar a Psicologia Social presente na Europa e inicia um amplo debate em que procura superar a dicotomia do individual e o social. Assim, Guareschi expõe, nesse artigo, as considerações de Moscovici acerca das lacunas que a Psicologia Social deixava em seus estudos, a partir do descaso com o ambiente social e sua influência sobre o indivíduo. Em seguida, o autor se atém à teoria das Representações Sociais (RS), refletindo sobre os elementos que a constituem e mostrando seu espaço dentro da Psicologia Social.

\footnotetext{
"Mestre em Educação pela UEPG. E-mail: pctolentino@uepg.br
}

Enfoca o pressuposto dessa teoria em trazer a linguagem do senso comum a uma teoria do conhecimento, na tentativa de "examinar como se formam os conhecimentos, como pensamos, com que pensamos, a partir do que pensamos" (p. 30), considerando necessário "tomar consciência de que não existe uma separação entre essa representação mental, o sujeito que conhece e o objeto conhecido" (p. 31). Dessa forma, a articulação entre as teorias sociológicas e psicológicas propostas por Moscovici a partir da teoria das RS faz com que se considere esta teoria como unificadora do campo da Psicologia Social, conforme conclui o autor.

Os artigos seguintes trazem investigações de fenômenos do cotidiano respaldadas tanto pela Psicologia Social como pela teoria das Representações Sociais, mostrando a amplitude de ambos os campos de conhecimento na discussão dos temas que envolvem a problematização do cotidiano. Marília Veríssimo Veronese apresenta a questão do consumo como categoria presente na produção cotidiana da vida. Aborda o debate do capitalismo globalizado contemporâneo, que trouxe aos tempos atuais uma ideologia em que o sujeito, dependendo do contexto, tem sua própria identidade ligada ao consumo: "em lugar do penso, logo existo, seria o consumo, logo existo" (p. 43). Os processos conscientes e inconscientes de grande complexidade estão na base das escolhas feitas pelos sujeitos, pois "desejos, crenças, representações e semantização singular do social estão por trás das escolhas de consumo" (p. 44). A autora discorre algumas teorizações sobre consumo nas Ciências Sociais desde Marx, passando por Canclini, Bourdieu, Baudrillard e Bauman, e comenta as críticas feitas pela Escola de Frankfurt à indústria cultural e às ideologias várias que compõem o cotidiano. Por sua experiência em investigações sobre economia solidária, que trata das questões ligadas ao trabalho em prol do bem-estar coletivo e seus produtos gerados de forma solidária e responsável ambientalmente, Veronese admite que a discussão das práticas de consumo é importante para a compreensão da produção e reprodução da vida social e privada, no sentido de uma forma mais solidária de viver. Referenciando Jovchelovitch, apresenta a Psicologia Social como ciência do entre, alegando que seu inquérito não é "nem o individual e nem o coletivo, mas o preciso ponto onde se relacionam as duas instâncias" (p. 56). 
Denise Amon e David Maldavski trazem ao âmbito da Psicologia Social o tema comida, considerando que, historicamente, a Psicologia abordou a comida de uma forma individualista, baseada no modelo mecanicista. Os autores realizam uma profunda revisão de literatura antropológica, sociológica e psicológica, enfatizando abordagens distintas da comida e das práticas da alimentação. A teoria das Representações Sociais é apontada como subsídio para a hipótese de que a comida pode ser narrativa social, trabalhando com o conceito de voz da comida, que trata das práticas alimentares como narrativa que possibilita trazer o contexto sócio-histórico dos sujeitos. $\mathrm{O}$ artigo menciona a pesquisa empírica que buscou conhecer os significados da comida e das práticas da alimentação para clientes e equipe de trabalho de um bistrô no sul do Brasil, em que se destaca a narrativa cotidiana da comida como nutrição e vida.

O significado do excesso corporal no cotidiano é o alvo da investigação de Lucia Stenzel. A desaprovação social que o excesso de peso provoca permite uma abordagem da doença não apenas "como fenômeno exclusivamente biológico, mas como um fenômeno sujeito às representações e forças ideológicas da sociedade" (p. 88). A autora revisita a história do corpo, trazendo as mudanças de representações do excesso de peso ao longo do tempo, as relações entre excesso e consumo, excesso e gênero. Traz também a questão do excesso como patologia e a construção do conceito de compulsão alimentar em uma discussão sobre a relação entre corpo, excesso, alimentação e cotidiano, buscando mostrar como as representações sociais do corpo e da alimentação estão relacionadas com as práticas cotidianas, e ajudando a entender o atualmente consolidado saber cotidiano sobre obesidade.

Uma discussão específica sobre o cotidiano dos psicólogos que atuam na área da saúde é o enfoque do estudo de Adriane Roso, salientando questões relacionadas à ética e trazendo ao debate a responsabilidade desses profissionais frente à saúde coletiva. Sua argumentação é pautada na Psicologia Social, juntamente com outras referências, como Freire, Boff e Focault, em um diálogo bem estruturado. A autora discute o sentido da cosmovisão, a visão de mundo de cada ser humano, que fornece significado àquilo que o cerca: "Essa visão de mundo é construída a partir de uma prática, de um colocar-se no mundo [...] o meu eu (as minhas decisões, o meu posicionamento diante de outros ethos) [...] está sempre inserido em um contexto que é construído sócio-historicamente" (p. 122). Nesse sentido, a cosmovisão adotada por esses profissionais que atuam na área da saúde se constitui no aspecto crucial da sua prática cotidiana. Em virtude disso, a autora convoca-os para uma reflexão sobre suas práticas, sugerindo um modelo de Psicologia Social da Saúde que, vendo o ser humano como pessoa-relação, se contrapõe àquele que vê o ser humano como indivíduo.

Sendo o trabalho uma realidade que perpassa o cotidiano das pessoas, os estudos a seguir trazem à discussão essa forma de atividade. Denise Carvalho Tatim faz considerações acerca da responsabilidade social empresarial - fenômeno recente, porém disseminado rapidamente, que polariza opiniões acerca do papel do empresariado nas causas sociais e ambientais. Sua análise sobre o tema é feita por intermédio da teoria das Representações Sociais de Moscovici e do conceito de Ideologia de Thompson, em que a autora traz o processo de construção estratégica de uma imagem socialmente responsável, mas que é muitas vezes constituída por mecanismos comerciais com objetivos econômicos. A construção de uma imagem associada à ideia de uma cidadania comprometida com a solução dos problemas sociais compõe a Representação Social da empresa capitalista, sempre acompanhada de boas qualificações por parte das pessoas. É identificada, assim, a estratégia ideológica das empresas que "criam uma Representação Social na qual desvinculam da sua imagem, e de seus produtos, os possíveis danos causados à sociedade" (p. 165).

O artigo seguinte vincula-se à discussão anterior, que analisa um projeto de responsabilidade social a partir da teoria das Representações Sociais. Maria Luisa Carvalho apresenta uma pesquisa empírica que aborda uma representação social específica: a Economia de Comunhão. Vinculada ao Movimento dos Focolares, essa representação é um movimento católico de origem italiana, proposto ao Brasil em 1991, com o objetivo de encontrar respostas ao problema da pobreza por meio do vínculo de empresários que doam parte dos seus lucros e adotam um código de ética com os demais sujeitos que participam do movimento, semelhante à responsabilidade social. A autora considera que o projeto de Economia de Comunhão expressa a lógica capitalista e que a raiz religiosa dificulta a possibilidade de crítica, pois são permeadas pela ideologia que reforça a relação de submissão por parte dos trabalhadores e pobres.

A relação de três variáveis - trabalho, destruição e consumo - e a forma como essas variáveis contribuíram para o estabelecimento da Modernidade e das transformações que constituem as múltiplas e poli facetadas possibilidades da pós-Modernidade são apresentadas por Marcus Witczak. O autor expõe os conceitos de trabalho, destruição e consumo, e introduz noções do que foi a Modernidade e como se processam os caminhos que levam à chamada pós-Modernidade, dialogando com a teoria social crítica, trazendo referências 
como Bauman e Castells, entre outros. Para ele, os homens produzem e reproduzem relações sociais conforme a imposição cultural de sua época. E as sociedades, que são produzidas pelas lutas e interesses desses mesmos homens, expressam todas as contradições da vida cotidiana. Quando se propuseram outros modos de pensar e sentir as relações cotidianas, tanto no Modernismo quanto no pós-Modernismo, as pessoas assumiram esses pressupostos e ressignificaram suas existências. Durante o texto, o autor relaciona tais aspectos com a Psicologia, que teve que se transformar, buscando definições e métodos que seriam mais apropriados a essa apreensão da realidade.

Helio Possamai e Pedrinho A. Guareschi apresentam uma investigação sobre as Representações Sociais do acidente de trabalho, uma vez que trata de um tema que gera sofrimento, desgaste, mutilações e morte. A investigação realizada pelos autores para entender esse fenômeno cotidiano foi subsidiada pela teoria das Representações Sociais e pelo conceito de Ideologia, e teve como sujeitos trabalhadores acidentados e não acidentados. Os resultados mostram que para todos os sujeitos os acidentes estão sempre relacionados à pessoa do trabalhador, por meio do descuido e da desatenção, entre outros fatores, em uma visão individualista. $O$ fatalismo é outro ponto que aparece nas falas dos sujeitos como pertencendo ao destino das pessoas. Os autores identificaram as mediações ocultadas em que se apresentaram as evidências de condições precárias de trabalho, pressões, coerções. Mesmo assim, as justificativas evidenciavam uma representação profundamente arraigada na sociedade, legitimando uma ideologia liberal na qual cada um é responsável pelo seu êxito e seu destino.

$\mathrm{O}$ artigo de Ney Bruck e Guareschi apresenta um estudo sobre o cotidiano do trauma, enfocando a questão do atendimento ao trauma psicológico nas emergências. Conforme os autores, o trauma vem adquirindo novos significados, influenciados por acontecimentos sociais recentes (como as catástrofes e os desastres), juntamente com situações-limite vividas pelas pessoas no cotidiano urbano. Eles dão ênfase à epistemologia a partir do entendimento da necessidade de preencher a superficialidade e a velocidade do modo de abordar temas complexos. Entendem que a noção da vulnerabilidade psicológica requer a identificação das representações sociais dos sujeitos envolvidos, de tal forma que a leitura da situação e a consequente ação rápida derivam da mobilidade dos fundamentos epistemológicos e da conexão disso tudo na prática. A primeira proposição colocada pelos autores, a epistemologia de si mesmo, pode trazer ao profissional uma elaboração crítica sobre os pressupostos que embasam sua ação, ao invés de simplesmente reproduzir o que tem sido feito na área. Uma segunda proposição, o não-redu- cionismo, traz a questão de se posicionar para uma ação condizente com os desafios postos por um acontecimento-limite. Somente esses conhecimentos não serão suficientes para uma intervenção nos momentos de crise psicológica, entretanto tal saber pode sugerir mudanças no modo de ver e autorizar modificações necessárias para o agir profissional.

Por fim, a questão da juventude é trazida no artigo de Caroline Zamboni com a intenção de problematizar a representação social da juventude. A autora discute o tratamento da Psicologia, que de uma forma geral trata dessa fase como um momento de crise, em que os comportamentos típicos são tolerados desde que cedam, ao seu tempo, espaço para o adulto bem adaptado, pressupondo um movimento linear no desenvolvimento humano. Em contraste com essa ideia, a autora considera a juventude como espaço de fronteira, a partir do pensamento de Boaventura de Souza Santos. A fronteira é um lugar distinto para convivência, as pessoas trazem consigo suas características de origem, mas precisam ressignificá-las para se relacionarem com os outros. Segundo a autora, "este conceito de fronteira possibilita que nos desvencilhemos de uma visão individualista das experiências que constituem o ser humano" (p. 279). A partir desta abordagem, a autora apresenta um trabalho empírico que descreve o processo de produção de um videoclipe por um grupo de jovens, com o objetivo de explicar o que é adolescência, colocando as representações sociais do grupo em movimento e promovendo o diálogo por meio da explicitação das diferenças.

Em conclusão, o livro Psicologia do cotidiano: representações sociais em ação traz ao leitor a pluralidade de temáticas que a Psicologia Social e a teoria das Representações Sociais se qualificam a discutir. A abordagem feita pelos autores foi desenvolvida, simultaneamente, de forma psicológica, sociológica, histórica e epistemológica, possibilitando um olhar completo à realidade complexa do cotidiano, fazendo dessa obra uma ótima referência para pesquisadores das Ciências Humanas e Sociais. Os pesquisadores em Educação já perceberam a importância de trazer as representações sociais dos diversos sujeitos que compõem o ambiente educacional aos seus trabalhos. E perceberam, também, que a compreensão das facetas do cotidiano a partir deste viés pode trazer um aprofundamento maior para o entendimento da dinâmica dos processos históricos, políticos e pedagógicos que envolvem as pesquisas na área da Educação. 